\title{
A PERGUNTA DE SPINOZA
}

\author{
Alex Leite ${ }^{1}$
}

RESUMO: O objetivo principal deste artigo é demonstrar que a iniciação filosófica de Spinoza começa com uma pergunta a respeito do bem verdadeiro. É uma pergunta apresentada aos leitores no De Intellectus. Dois interesses animam a indagação: 1) alterar a maneira como certos bens são desejados e 2) compartilhar uma investigação a respeito do que pode ser mais desejado.

PALAVRAS-CHAVE: Spinoza; pergunta; TIE; bem; iniciação.

ABSTRACT: The main goal of this article is to demonstrate that the Spinoza's philosophical initiation begins with a question about the true good. It is a question presented to readers in De Intellectus. Two interests instigate the question: 1) change the way certain goods are desired and 2) share a research about what may be more desired.

KEYWORDS: Spinoza; question; TIE; good; initiation. 
Spinoza, no De Intellectus, pergunta qual é o nosso verdadeiro bem. ${ }^{2}$ Trata-se de uma indagação que une o interesse do autor ao possível leitor já interessado em refletir sobre os bens mais estimados na vida em comum. A indagação possibilita um contato entre o autor e o leitor, mas isso desde que a relação entre o desejo e qual é o melhor dos bens se torne um problema.

Segundo Alexandre Koyré, a indagação suscita o elo entre autor e o leitor porque o problema faz parte da experiência comum. ${ }^{3}$ Já Bernard Rousset ${ }^{4}$ observa que há o uso da primeira pessoa no início do De Intellectus. Há uso do me (postquam me Experientia) como estratégia retórica $\mathrm{e}$ pedagógica. Assim, para ele, o modo da pergunta transforma a experiência individual em um problema que pode ser compartilhado pelo leitor.

Ora, a indagação torna-se tanto mais eficiente quanto mais se percebe o ponto de interseção entre o problema que ela resguarda e o interesse comum. E Spinoza procura pensar a partir de um ponto de interseção, pois a investigação sobre o nosso verum bonum poderá ser compartilhável. ${ }^{5}$ Para ele, a experiência de tal percurso poderá corresponder à fruição compartilhada de uma alegria maior. ${ }^{6}$

De fato, a pergunta a respeito do verum bonum abre um campo de interesse a respeito do que é mais útil desejar. Mas o elemento essencial que unirá esse campo é a 
exigência de conceber a noção do Ser perfeitíssimo. ${ }^{7}$ Ora, embora o De Intellectus não trate de noções comuns, como sugere a hipótese de Gilles Deleuze ${ }^{8}$, já ali se procura pensar a constituição da existência segundo um ponto de interseção em que a reflexão sobre o ético e o cognitivo poderá ser unificada. Certamente, o estilo do De Intellectus não possui o caráter proposicional da Ethica. No entanto, o De Intellectus abrirá a possibilidade de pensar as relações entre as coisas segundo a perspectiva de uma interseção essencial. ${ }^{9}$ Pensamento esse que não deixará de fora o conhecimento das diferenças, concordâncias e oposições ${ }^{10}$ entre as coisas. Ora, ao mesmo tempo em que a indagação sobre o verum bonum abre um campo de reflexão sobre o que é mais útil desejar, abre ainda o interesse de conhecer o ponto de ligação entre os seres humanos.

Ainda sobre a pergunta inicial do De Intellectus, Lívio Teixeira refere-se a ela como "uma angustiosa indagação."11 Há, sem dúvida, um aspecto tenso na indagação, uma vez que ela exige a percepção do próprio momento e a possibilidade de enveredar por um caminho ainda incerto. ${ }^{12}$ É uma incerteza momentânea, nascida da indecisão de seguir um percurso que exigia a saída da passividade perante bens certos, para efetivar uma nova exigência afetiva. Assim, um sentido de transição emerge, e a indagação abre o caminho. A pergunta torna-se uma iniciação ao pensamento, uma vez que ela sintetiza a 
situação limite do autor. É um momento em que Spinoza avalia uma forma de ela ser instituída e a possibilidade de experimentar um novo caminho. Assim, a força da pergunta instaura uma fronteira entre a aceitação dos valores atribuídos aos bens dados e a reformulação desses valores.

Portanto, o ponto central da indagação é a sua capacidade de atuar logo no início do De Intellectus como revelador de uma crise. A ideia de crise está intimamente ligada ao tema da decisão e à possibilidade da alegria contínua. Assim, surge gradativamente uma reflexão sobre como constituir um novo percurso existencial. E a característica marcante da crise é a percepção de que outro sentido a respeito da ordem dos bens se impõe em relação ao que comumente era aceito. É o momento em que uma nova exigência se impõe. Ora, operava-se dentro de uma forma instituída do desejo, e a possibilidade de alterar a forma emerge com uma determinada força. Assim, nasce a incompatibilidade entre o modo como frequentemente se desejavam certos bens e uma nova exigência do desejo. É uma passagem tensa. É tensa uma vez que não é mais possível operar segundo a forma vigente de desejar. De fato, outro modo de sentir e perceber os bens começa a ganhar espaço na mente. E a crise evoluirá no sentido de que um caminho mais árduo se abrirá na mesma medida em que o caminho anterior não poderá ser mais trilhado. 
O caminho mais árduo será o da experiência do pensamento autônomo e o da organização existencial que possibilite o exercício pleno dessa experiência. Segundo Bernard Rousset, o pensamento que emergirá da crise promoverá uma reflexão ética. Para ele, trata-se, sobretudo, de uma descoberta que encaminhará Spinoza a uma vida do espírito. ${ }^{13}$ Pensamos que o exercício do pensamento e a organização existencial são dois movimentos justapostos, mesmo que esse último seja silencioso. Não há trabalho do entendimento sem que as condições existenciais estejam em pleno acordo com o que tal atividade exige. A própria reflexão sobre o verum bonum envolverá a ideia de um novo uso dos bens mais frequentes e, consequentemente, outra forma de relação com esses bens.

O modo como o problema do verum bonum é colocado parece-nos retomar o sentido iniciático, já posto por Sêneca. ${ }^{14} \mathrm{Na}$ exposição inicial do De vita beata, Sêneca lança uma problemática a respeito do que é o viver feliz. O tema exigirá uma investigação, e o modo como é colocado envolverá o acompanhamento de outra pessoa, no caso, ali, o irmão Galião. Trata-se de estabelecer um plano radical de investigação comum. Tanto o início do De Intellectus quanto o do De vita beata possui um tom permeado pela dramaticidade da vida humana. Esse tom deve ressaltar que o valor do tema, seja o verdadeiro bem ou a vida feliz, 
encontra-se na possibilidade de tornar o objeto de interesse do filósofo conveniente aos não-filósofos.

A ação de indagar o tema do verum bonum implica um sentido de pertencimento ao conjunto da vida corrente. Esse sentido é um elemento capaz de fazer-nos ultrapassar a condição de isolamento que a imaginação supostamente poderá forjar. Assim, a interlocução mediada pela questão do verum bonum resguarda um ponto de interseção, que interliga a vida humana. É o momento de ligação entre a experiência individual e o conjunto no qual estamos inseridos. Ora, a singularidade é tanto mais forte quanto mais o sentido de pertencimento é conhecido e compartilhado. Assim, podemos afirmar que a indagação é o marco de uma transição em que a verdade do ser se constituirá através da superação da individualidade abstrata, expressa por um eu, para apropriar-se de um sentido que se expressará como summum bonum ${ }^{15}$, ou seja, como fruição compartilhada de percepções ativas.

Entretanto não é possível perceber o sentido de pertencimento sem observar um traço de tensão marcado pelo contraponto existente entre a noção vulgar de "bens supremos"16 e a noção de summum bonum. E não se trata de uma tensão entre os bens reais e o bem ideal; é, na verdade, um esforço de desativação do modo de desejar os bens mais frequentes como fins em si mesmos, para desejá-los como meios. ${ }^{17} \mathrm{~A}$ base dessa superação se encontra na percepção 
nascente do verum bonum e do summum bonum. Ora, o fato é que a mudança dos bens da condição de fins para meios altera no plano ético, a forma da relação com o outro. Nesse sentido, o recurso retórico ${ }^{18}$ usado por Spinoza, para aproximar o De Intellectus de possíveis leitores, é uma estratégia de aproximação do outro, mediada pela reflexão, pelo entendimento. Enfim, a ação que a pergunta a respeito do verum bonum tende a produzir pode ser pensada como amizade, no sentido de interseção mediada pelo interesse de conhecer as condições de fortalecimento dos elos humanos e, assim, de fruição compartilhada de uma alegria liberada de toda tristeza. ${ }^{19}$

\section{NOTAS}

${ }^{1}$ Professor Adjunto da Universidade do Estado da Bahia (Uneb). Doutor em Filosofia pela Universidade Federal do Rio de Janeiro (UFRJ). E-mail: alexjeq@hotmail.com.

${ }^{2}$ Cf. TIE 1: constitui tandem inquirere, an aliquid daretur, quod verum bonum / "decidi, finalmente, indagar se existia algo que fosse um bem verdadeiro." Trad.: Lívio Teixeira, 1966.

${ }^{3}$ Cf. Alexandre Koyré. Avant-propos, 1994, p. XIX, XX: "Le théme vero bono [...] est, en effet, vieux comme le monde. Ce n’est pas son histoire personnelle que nous revele Spinoza. C'est l'expérience commune et général de l'homme". 


\section{A PERGUNTA DE SPINOZA}

${ }^{4}$ Cf. Bernard Rousset. Commentaire, 1992, p. 149: "En effet, une expérience peut être personnelle et avoir un contenu traditionel [...] et ce Je sera tantôt réelement personnel, faisant état de l’homme Spinoza (on penserait à Montaigne), tantôt rhétoriquement personnel, faisant intervir le philosophe Spinoza (on pense à Descartes), tantôt pédagogiquement personnel (un Nous comme Je commum avec le lecteur).

${ }^{5}$ Cf. TIE 1: et sui communicabile esset / "et qui pût se partager". Trad.: Bernard Pautrat, 2009.

${ }^{6} \mathrm{Cf}$. TIE 14: mea felicitate.

${ }^{7}$ Cf. TIE 49: Unde initio illud erit maxime observandum, ut quanto ocius ad cognitionem talis Entis perveniamus / "Dès le début donc, il nous faudra veiller principalement à ce que nous arrivions le plus rapidement possible à la connaissance d'un tel Etre." Trad.: Alexandre Koyré, 1994.

${ }^{8}$ Cf. Gilles Deleuze. Spinoza - philosophie pratique. Paris: Minuit, 1981, p. 154: "En effet, il apparaît que les notions communes sont un apport propre de 1'Ethique. Elles n'apparaissaient pas dans les ouvrages précédents."

${ }^{9}$ Cf. TIE 110: "deve-se estabelecer alguma coisa comum da qual derivam as propriedades das coisas".

${ }^{10}$ TIE 25, II: differencias, convenientias, et oppugnantias.

11 Cf. Espinosa, Tratado da reforma da inteligência; tradução, introdução e notas de Lívio Teixeira, São Paulo: Martins Fontes, $2^{\mathrm{a}}$ ed., 2004, p. XI: "a reforma da inteligência começou com uma angustiosa indagação a respeito do Bem Supremo."

${ }^{12}$ TIE 2: "deixar o certo pelo incerto."

${ }^{13}$. Cf. Rousset, Op. cit. p. 148: "la Philosophie ne sera développé que dans la mesure où elle apporte une solution à la question du bien suprême, dans un enseignement moral, une Ethique. Elle ne pourra, également, pas consister en un renvoi à l’action: parce qu'il s'agit de 


\section{REVISTA IDEAÇÃ0, EDIÇÃO ESPECIAL 2018}

jouir d'une félicité, elle renvoi à une vie de l'esprit, qui trouvera son repos dans l'immanence de la réflexion et de l'entendement."

${ }^{14}$ Cf. Sêneca, Sobre a vida feliz, tradução, introdução e notas de João Teodoro d'Olim Marote, edição bilíngue, São Paulo: Nova Alexandria, 2005, p. 19: "Viver feliz, meu irmão Galião, todo mundo quer, mas ninguém sabe ao certo o que torna a vida feliz."

${ }^{15}$ Cf. TIE 13. A definição de summum bonum envolve a ideia de fruição compartilhada da alegria contínua. Fruir no sentido de experimentar com outros a alegria da descoberta do que é a união da mente e a Natureza.

${ }^{16}$ Cf. TIE 3: divitias scilicet, honorem, atque libidinem / "riquezas, honras e sexo."

${ }^{17}$ Cf. TIE 11: tanquam media.

18 Cf. Theo Zweerman, 1993, p. 6: "comment persuader le lecteur d'effetuer cette transition en compagnie de l'auteur."

19 Cf. TIE 10: Sed amor erga rem aeternam, et infinitam sola laetitia pascit animum, ipsaque omnis tristitiae est expers / "Mas o amor por uma coisa eterna e infinita nutre o ânimo unicamente de alegria, liberada de toda tristeza." 


\section{REFERÊNCIAS BIGLIOGRÁFICAS}

DELEUZE, Gilles e GUATTARI, Félix. O que é a filosofia? Tradução de Bento Prado Jr. e Alberto Alonso Muñoz. Rio de Janeiro: Ed. 34, 1992.

DELEUZE, Gilles. Spinoza. Philosophie pratique. Paris: Minuit, 1981.

DELEUZE, Gilles. Spinoza et le Problème de l'expression. Paris: Les Editions de Minuit, 1968.

MATHERON, A. Pourquoi le TIE est-il inachevé? In Revue de Sciences Philosofiques e Théologiques, 1987.

MATHERON, A. Les Modes de Connaissance du T.R.E. et les genres de connaissance de l'Éthique, in Spinoza, Science et Religion; Colloque de Cerisy. Paris, 1988.

SANTIAGO, Homero. $O$ mais fácil e o mais difícil: A experiência e o início da Filosofia. Em Revista Conatus, v. 1 $\mathrm{n}^{\circ}$ 2, p. 37. Fortaleza: Universidade Estadual do Ceará, 2008.

SÊNECA. Sobre a vida feliz. Tradução, introdução e notas de João Teodoro d'Olim Marote, edição bilíngue. São Paulo: Nova Alexandria, 2005.

SPINOZA, B. Traité de la reforme de l'entendement. Traduciton, introduction et commentaire de B. Rousset, J. Vrin. Paris, 1992. 
- Ética. Edição bilíngue latim-português.

Tradução de Tomaz Tadeu. Belo Horizonte: Autêntica Editora, 2007.

. Traité de la réforme de l'entendement. Texte, traduction et notes par Alexandre Koyré. Paris: Vrin, 1994.

. Tratado da reforma do entendimento. Edição bilíngue latim-português. Tradução de Abílio Queiróz. Lisboa: Edições 70, 1969.

- Tratado sobre a reforma do entendimento. Tradução, prefácio e notas de António Borges Coelho. Lisboa: Livros Horizonte.

- Traité de la réforme de l'entendement. Introduction, traduction et commentaires par André Lécrivain. Paris: Flammarion, 2003.

. Oeuvres Complètes. Traduction, présentacion et notes par R. Caillois, M. Francês et R. Misrahi. Paris, Gallimard/Plêiade, 1954.

- Oeuvres de Spinoza I. Présentation, traduction et notes par Charles Appuhn. Paris: Flammarion, 1964.

. Obras Incompletas. Consultoria de Marilena de Souza Chaú. São Paulo: Nova Cultura, 1997.

. Tratado de la reforma del entendimiento y otros escritos. Estúdio preliminar, traducción y notas de Lelio Fernández y Jean Paul Margot. Madrid: Tecnos, 1989. 
A PERGUNTA DE SPINOZA

Tratado da reforma da inteligência. Tradução, introdução e notas de Lívio Teixeira. $2^{\mathrm{a}}$ ed. São Paulo: Martins Fontes, 2004.

ZWEERMAN, Theo. L'introduction a la philosophie selon Spinoza. Une analyse structurelle de l'introduction du Traite de la Reforme de l'Entendement suivie d'un commentaire de ce texte. Louvain: Presses Universitaire de Louvain, 1993. 